\title{
Poor Prognosis Factors of Severe Malaria in Antananarivo, Madagascar
}

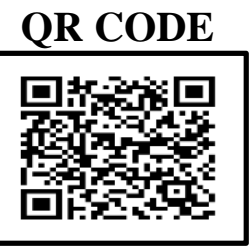

\section{JASPER GRANT RAELISON ${ }^{*}$, HANITRA MBOLATIANA RIVOARIMANANA², TANJONIRINA RAZAFINDRAINIBE ${ }^{3}$, NADIA MARIE PHILIBERTINE RAHANITRINIAINA ${ }^{3}$, FALIHERY ALBERTIN RAKOTOMAVO', NASOLOTSIRY ENINTSOA RAVELOSON ${ }^{1}$}

INTRODUCTION \& AIM: Malaria is a major health problem in our country. Our aim is to determine the poor prognosis factors of this pathology. MATERIALS AND METHOD: A retrospective descriptive, analytical study was conducted in the intensive care unit of University Hospital Center of Joseph Raseta Befelatanana, during 24 months (June 2015 to May 2017). The severity was defined according to the recommendations for clinical practice (2007). We compared surviving and non-surviving patients.

RESULTS: Fifty-six (56) cases were studied. The average age was $30 \pm 11$ years with a sex ratio of 6 . Six cases had pulmonary disease. Neurological failure was present in 29 cases. Forty-seven cases were treated with quinine and 07 cases received norepinephrine. The length of stay was $3.55 \pm$ 2.06 days. Eighteen subjects $(32 \%)$ died. In multivariate analysis, neurological failure $(p=0.0001)$, jaundice $(p=0.0016)$, renal insufficiency ( $p$ $<0.0001)$ and use of catecholamine $(\mathrm{p}=0.0139)$ were associated with poor prognosis.

CONCLUSION: The mortality of malaria was high. Neurological failure, jaundice, renal insufficiency and use of catecholamine were poor prognostic factors.

KEYWORDS: Intensive Care Unit, Mortality, Poor Prognosis Factors, Severe Malaria

\section{INTRODUCTION}

Malaria is a major public health problem in endemic tropical regions. It affected 212 million new people and caused 429,000 deaths in 2015 in the world. ${ }^{1}$ The mortality in developed countries was low. The neurological failure, acute respiratory distress syndrome and mechanical ventilation ${ }^{2}$, age, and hyperparasitaemia ${ }^{3}$ were the factors associated with mortality. But in Africa, the mortality was around 16 to $32 \% .4,5$ Age $>65$ years, coma, seizures, macroscopic hemoglobinuria ${ }^{5}$ and cardiogenic shock were the poor prognostic factors. ${ }^{5}$ Our aim is to determine the factors of poor prognosis of this disease.

\section{MATERIALS AND METHOD}

This is an analytical descriptive retrospective study conducted over a period of 24 months (June 2015 to May 2017). It was performed in Intensive Care Unit of University Hospital Center of Joseph Raseta Befelatanana.

Patients' inclusion criteria was: 18 years of age, those who were diagnosed and tested positive for Plasmodium by peripheral blood smears, quantitative buffy coat test, had one or more criteria of severe malaria as per the Recommendations for clinical practice (2007). ${ }^{6}$
Variables included age, gender, comorbid condition, severe malaria severity criteria's, treatment, the duration of hospitalisation and mortality.

The study was reviewed and approved by the Ethical Review Board of the Medical Intensive Care Unit of the University Hospital Center of Joseph Raseta Befelatanana. Data were collected and entered in Microsoft Excel 2016. Continuous variables were represented by mean and standard deviation, and categorical variables were represented by number and frequency. The t-student test was used to analyse continuous variables and chi-square test for analysis of categorical variable. The $\mathrm{p}$ value was considered as significant if less than 0.05 .

\section{RESULT}

A total of 56 patients were reviewed. The mean age was $30 \pm 11$ years. Out of the total subjects, 48 were males. Sex ratio was found to be 6 . A total of o6 cases had respiratory comorbidities.

Twenty nine (52\%) developed neurological failure. The circulatory failure and jaundice were observed in 17 (30\%) and $16(29 \%)$ cases respectively. Severe anaemia was present in $14(25 \%)$ cases, $5(9 \%)$ cases had 
hyperparasitaemia.

$47(84 \%)$ patients received quinine. Twelve (21\%) cases were given norepinephrine. The average length of ICU stay was $3.55 \pm 2.07$ days. The mortality proportion was $32 \%$ (18 cases). (Table 1 )

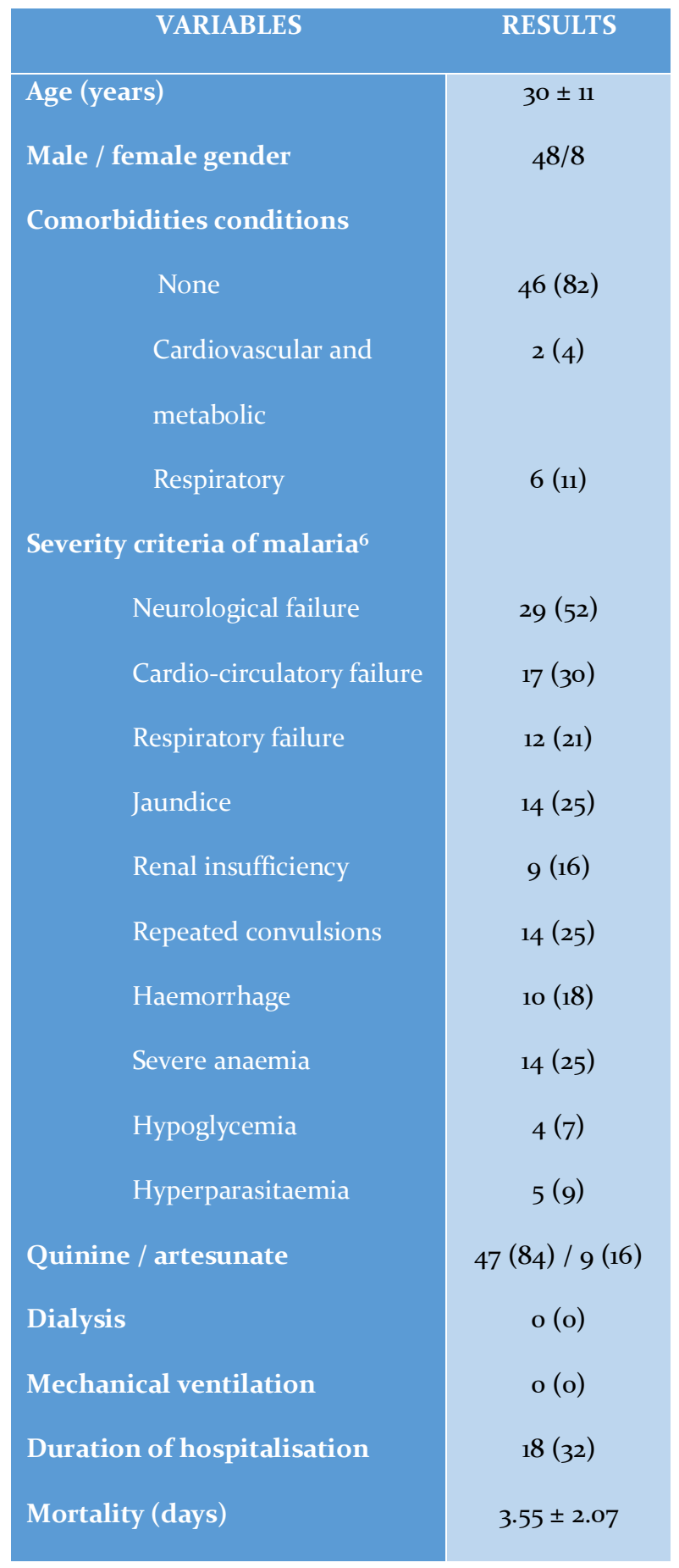

Table 1. Clinical \& Microbiological Characteristics and Treatment of Severe Malaria
In multivariate analysis, neurological failure, jaundice, renal insufficiency and use of catecholamine were factors associated with poor prognosis (Table 2).

\section{DISCUSSION}

In this study, neurological failure was by far the most common. The mortality proportion was $32 \%$. Neurological failure, jaundice, renal insufficiency and use of catecholamine represented as mortality risk factors.

The mortality proportion was $32 \%$ : 16 to $33 \%$ in Africa $^{4,5,7}$, low in India ${ }^{8,9}$ and developed country ${ }^{2,3,10,11}$. This difference could be explained by the untimely diagnosis and treatment of patients. ${ }^{12}$ All patients were transferred from rural endemic regions to the hospital. The neurological failure was the most common sign $^{3,5,7,13}$ and was among the factors of poor prognosis: a result confirmed by the literature. . $^{3,9,13}$

Jaundice has been reported as a risk factor: result confirmed by literature. ${ }^{13,14}$ It is due to liver dysfunction ${ }^{\text {"1 }}$ and lysis of red blood cells.

The renal insufficiency was observed as a factor of poor prognosis: a result confirmed by some authors. ${ }^{5,9,11}$ None of our patients underwent haemodialysis because they had no money. The haemodialysis rate varied from 10 to $35^{\%}$ in the literature, ${ }^{3,9-11}$ with acute renal failure in $48 \%$ of subjects. ${ }^{9,15}$ The lack of dialysis increased death rate. ${ }^{16}$ The aetiology was multifactorial including hypovolemia, disseminated intravascular coagulation, haemolysis and hyperbilirubinemia. ${ }^{17}$

The use of amines was a risk factor associated with mortality and consistent with other reported series. ${ }^{3,4,9}$

This retrospective study predicted the poor factors associated with death in severe malaria. It was the first study conducted in a medical ICU of Madagascar. Despite the small sample size, it did not predict the overall assessment of the Malagasy population in intensive care.

\section{CONCLUSION}

The morbidity and mortality of malaria remains a major problem in tropical countries. No study evaluated factors associated with poor prognosis in Madagascar. Mortality remains high in our study with factors associated with poor prognosis such as jaundice, neurological failure, use of catecholamine and renal insufficiency. 


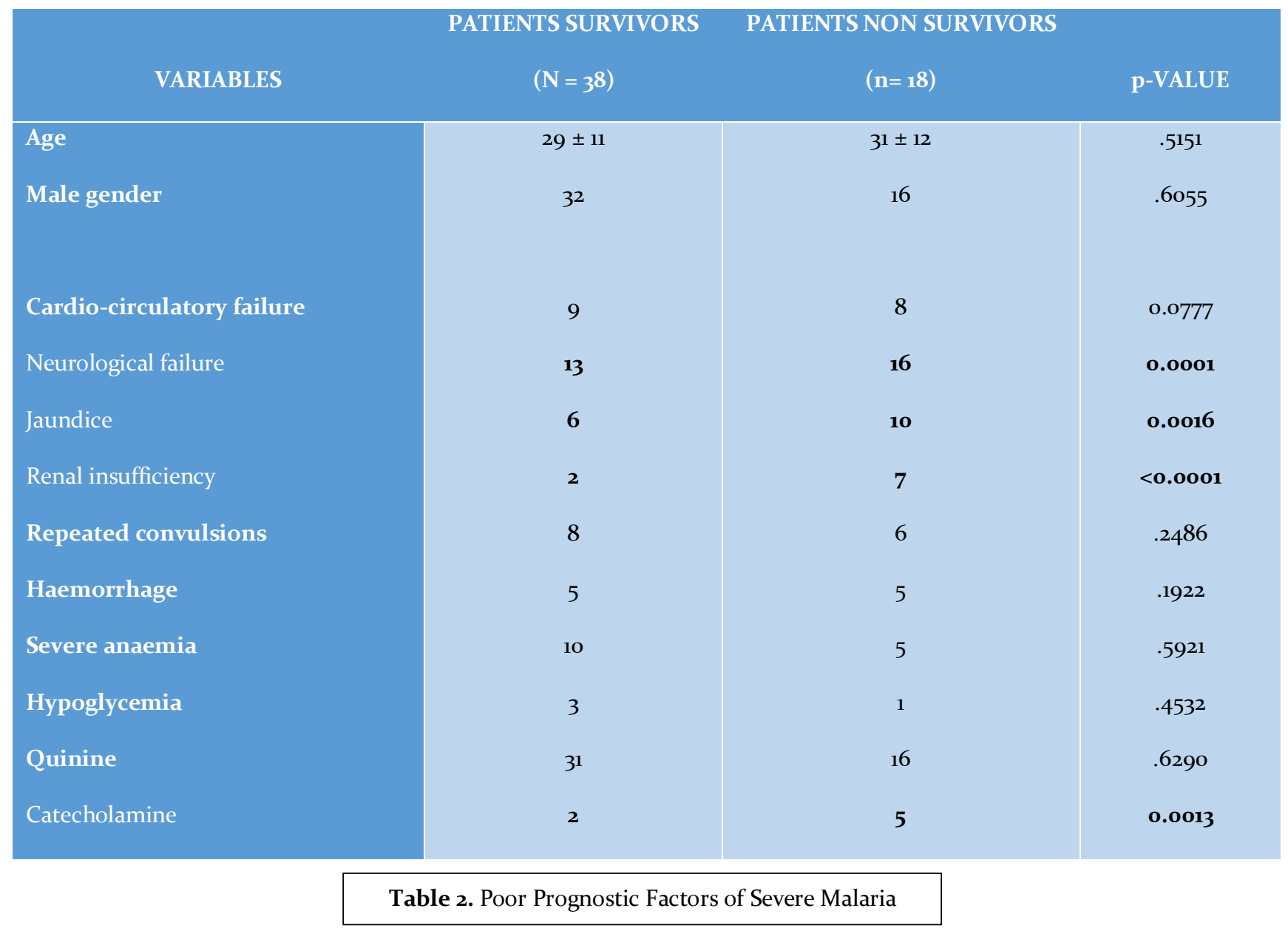

\section{REFERENCES}

1. Organisation Mondiale de la Santé. Journée mondiale de lutte contre le paludisme 2017: principaux messages. 2017;1-5.

2. Kurth F, Develoux M, Mechain M, Malvy D, Clerinx J, Antinori S, et al. Severe malaria in Europe: an 8-year multi-centre observational study. Malar J. 2017;16(1):57.

3. Bruneel F, Tubach F, Corne P, Megarbane B, Mira JP, Peytel E, et al. Severe imported falciparum malaria: a cohort study in 400 critically ill adults. PloS One. 2010;5(10):e13236.

4. Wade KA, Sene BEJ, Niang EM, Diallo A, Diatta B. Epidémiologie et valeurs pronostiques de des défaillances viscérales au cours du paludisme grave à l'hôpital d'instruction des armées principal de Dakar, Sénégal. Med Sante Trop. 2012;22(4):422-4.

5. Eholié SP, Ehui E, Adou-Bryn K, Kouamé KE, Tanon A, Kakou A, et al. Paludisme grave de l'adulte autochtone à Abidjan (Côte d'Ivoire). Bull Soc Pathol Exot 1990. 2004;97(5):340-4.
6. Recommendations for clinical practice. Management and prevention of imported Plasmodium falciparum malaria. (Revision 2007 of the 1999 consensus conference). Short text. Med Mal Infect. 2008; 38:54-67. 7. El Mezouari EM, Belhadj A, Ziani M, Boughanem M, Moutaj R. Le paludisme grave d'importation chez l'adulte : étude rétrospective de treize cas admis en réanimation à Marrakech. Pan Afr Med J. 2016;25:179. 8. Kathirvel S, Tripathy JP, Tun ZM, Patro BK, Singh T, Bhalla A, et al. Physicians' compliance with the National Drug Policy on Malaria in a tertiary teaching hospital, India, from 2010 to 2015: a mixed method study. Trans R Soc Trop Med Hyg. 2017;111(2):62-70.

9. Saravu K, Rishikesh K, Kamath A. Determinants of mortality, intensive care requirement and prolonged hospitalization in malaria - a tertiary care hospital based cohort study from South-Western India. Malar J. 2014;13:370.

10. Marks ME, Armstrong M, Suvari MM, Batson S, 
Whitty CJM, Chiodini PL, et al. Severe imported falciparum malaria among adults requiring intensive care: a retrospective study at the hospital for tropical diseases, London. BMC Infect Dis. 2013;13:118.

11. Valance D, Vandroux D, Antok E, Winer A, Gaüzère B-A. Caractéristiques cliniques du paludisme sévère d'importation de l'adulte à la Réunion de 2000 à 2011. Anesth Réanimation. 2015;1(4):305-12.

12. Mphahlele BJ, Mpe MJ. Falciparum malaria in a South African tertiary care hospital. Pol Arch Med Wewn. 2008;118(6):351-5.

13. Arslan F, Mert A, Batirel A, Inan A, Balkan II, Nazlican $\mathrm{O}$, et al. Imported Plasmodium falciparum malaria in Istanbul, Turkey: risk factors for severe course and mortality. Trop Doct. 2013;43(4):129-33.
14. von Seidlein L, Olaosebikan R, Hendriksen ICE, Lee SJ, Adedoyin OT, Agbenyega T, et al. Predicting the clinical outcome of severe falciparum malaria in african children: findings from a large randomized trial. Clin Infect Dis Off Publ Infect Dis Soc Am. 2012;54(8):1080-90.

15. Saravu K, Rishikesh K, Parikh CR. Risk factors and outcomes stratified by severity of acute kidney injury in malaria. PloS One. 2014;9(3):e90419.

16. Trang TT, Phu NH, Vinh H, Hien TT, Cuong BM, Chau TT, et al. Acute renal failure in patients with severe falciparum malaria. Clin Infect Dis Off Publ Infect Dis Soc Am. 1992;15(5):874-80.

17. Maheshwari A, Singh AK, Sinha DK, Tripathi K, Prakash J. Spectrum of renal disease in malaria. J Indian Med Assoc. 2004;102(3):143, 146, 148 passim. 